\title{
Cortoplacismo societario como una expresión del modelo de primacía de los accionistas y la necesidad de repensar dicho modelo: Estados Unidos y Colombia
}

\author{
Corporate Short-Termism as an \\ Expression of the Shareholder Primacy \\ Model and the Need to Rethink It: The \\ United States and Colombia
}

Curtoprazismo corporativo como expressão do modelo da primazia dos acionistas e a necessidade de repensá-lo: Estados Unidos e Colômbia

Daniela Alvarado Guzmán*

Lina López Gómez ${ }^{* *}$

* $\quad$ https://orcid.org/0000-0001-9197-7287. Grupo Élite contra Colusiones de la Delegatura de Protección de la Competencia, Superintendencia de Industria y Comercio. alvaradodaniela@javeriana.edu.co

** https://orcid.org/0000-0002-1708-4672. Gerente de Asuntos Legales y Recursos Humanos, Condimentos El Rey. 1_lopez@javeriana.edu.co

Recibido: 12/06/2021. Envío a pares: 02/08/2021 Aprobado por pares: 28/09/2021. Aceptado: 30/09/2021

DOI: 10.5294/dika.2021.30.2.6 


\section{Resumen}

El cortoplacismo societario es una expresión del modelo de primacía de los accionistas, el cual se abordará desde su aplicación en Estados Unidos y Colombia. El incremento de las ganancias de los accionistas a corto plazo podría, según el caso, generar externalidades negativas en otros stakeholders y poner en riesgo el futuro de la compañía y las inversiones de los propios accionistas a largo plazo. De allí que resulte pertinente y necesario repensar dicho modelo para adoptar el stakeholder model y asignar a los administradores un rol mediador entre las diferentes partes interesadas. Adicionalmente, los accionistas también deben asumir responsabilidad y es momento de comenzar a discutir sobre la asignación de deberes expresos para ellos, más allá de la buena fe y la prohibición de abusar de los derechos, como ocurre para el caso de los administradores.

\section{Palabras clave}

Cortoplacismo; problemas de agencia; shareholder primacy model; stakeholder model. 


\section{Abstract}

Corporate short-termism is an expression of the shareholder primacy model, analyzed from its application in the United States and Colombia. Increased shareholder earnings in the short term could give rise to negative externalities in other stakeholders and jeopardize the future of the company and the investments of the shareholders themselves in the long term. Hence, it is relevant and necessary to rethink this model, adopt the stakeholder model, and provide managers with a mediating role between the different stakeholders. Additionally, shareholders must be held accountable; it is time to start discussing the assignment of express duties to them, beyond good faith and the prohibition of abusing rights, as is the case of managers.

\section{Keywords}

Short-termism; agency problems; shareholder primacy model; stakeholder model. 


\section{Resumo}

O curtoprazismo corporativo é uma expressão do modelo da primazia dos accionistas, que será abordada a partir de sua aplicação nos Estados Unidos e na Colômbia. $\mathrm{O}$ aumento dos ganhos para os acionistas no curto prazo pode, segundo o caso, gerar externalidades negativas nos demais stakeholders e colocar em risco o futuro da empresa e os investimentos dos próprios acionistas no longo prazo. Portanto, é pertinente e necessário repensar esse modelo para adotar o modelo de stakeholders e atribuir aos administradores um papel mediador entre os diferentes stakeholders. Além disso, os acionistas também devem assumir a responsabilidade e é hora de começar a discutir a atribuição de deveres expressos para eles, o que vai mais além da boa-fé e da proibição de abuso de direitos, como é o caso dos administradores.

\section{Palavras-chave}

Visão de curto prazo; problemas de agência; modelo da primazia do acionista; modelo das partes interessadas; modelo de stakeholders. 
Sumario: Introducción. 1. Precisiones conceptuales. 2. Estados Unidos: el modelo de primacía de los accionistas y el cortoplacismo societario en los casos Dodge contra Ford, Valeant y Enron. 3. Colombia: la necesidad de repensar el modelo y consagrar no solo derechos sino deberes de los accionistas para mitigar los problemas de agencia y el cortoplacismo societario. Conclusiones. Bibliografía.

\section{Introducción}

Colombia y Estados Unidos son países donde difiere la forma en la que está organizado el capital de la mayoría de las compañías constituidas en estos territorios. Mientras que en Colombia priman las sociedades con capital concentrado, en Estados Unidos prevalecen las compañías con capital disperso. No obstante, en ambas jurisdicciones el modelo de primacía de los asociados (shareholder primacy model) se impone sobre el modelo según el cual las sociedades son instituciones que sirven para múltiples propósitos y, por tal razón, no deben perseguir solamente los intereses de los asociados, sino que también deben considerar el bienestar de otras partes interesadas (stakeholder model). Al analizar el caso de Estados Unidos, se exponen los riesgos de la aplicación de este modelo en Colombia donde rige un Estado social de derecho.

La prevalencia del shareholder primacy model genera que en la toma de decisiones sociales, en la mayoría de las ocasiones, se anteponga el cortoplacismo societario sobre las consideraciones de largo plazo que también son importantes y podrían definir el futuro de la compañía y el bienestar de los accionistas. ${ }^{1} \mathrm{De}$ esta manera, se acentúan los problemas de agencia que el derecho de sociedades pretende solucionar.

Como se verá a lo largo de este artículo, los stakeholders, como principales, ven afectado su bienestar por la conducta de los agentes: ${ }^{2}$ la compañía, sus administradores y accionistas que priorizan sus beneficios en el corto plazo en la toma de decisiones, lo cual podría generar externalidades negativas para las otras partes interesadas. Adicionalmente, el cortoplacismo societario puede incrementar los problemas de agencia entre los accionistas y la compañía y, por ejemplo, el interés de algunos accionistas (agente) en el corto plazo puede ser el reparto excesivo de dividendos por encima de realizar inversiones que beneficiarían a la compañía (principal) en el largo plazo. Asimismo, el cortoplacismo societario genera que los administradores (agentes) busquen aumentar excesivamente el precio de las acciones listadas en bolsa, aunque esto pueda afectar los intereses de los accionistas (principal) en el largo plazo y de otros stakeholders (principal). 
Por esta razón, a partir de una metodología cualitativa y comparativa se estudiará la aplicación del shareholder primacy model en Colombia y Estados Unidos. Así, se demostrará que para mitigar los problemas de agencia que nacen de la aplicación de este modelo, principalmente por el impacto que ello podría generar en otros stakeholders, es necesario repensarlo y abogar por el stakeholder model. En consecuencia, resultaría pertinente promover una visión según la cual las compañías comiencen a guiar su actuación persiguiendo los intereses de la totalidad de las partes interesadas $y$, para ello, el administrador debe actuar como un mediador entre los diferentes stakeholders. Además, es necesario dialogar en la academia acerca de los deberes que tienen los accionistas con la compañía y con los demás grupos de interés.

Para demostrar que el cortoplacismo societario es una expresión del modelo de primacía de los accionistas, y plantear la necesidad de repensar dicho modelo para adoptar el stakeholder model, en primer lugar se definirán para el lector las palabras clave de este trabajo: shareholder primacy model, stakeholder model, cortoplacismo societario y los problemas de agencia. En segundo lugar, se verá el modelo de primacía de los accionistas y el cortoplacismo societario en los casos Dodge contra Ford, Valeant Pharmaceuticals International Inc. y Enron en Estados Unidos. En tercer lugar, se verá el shareholder primacy model en Colombia y se tratará la necesidad de repensar el modelo y consagrar no solo derechos, sino deberes de los accionistas para mitigar los problemas de agencia y el cortoplacismo societario. Finalmente, se presentarán las conclusiones del trabajo.

\section{Precisiones conceptuales}

En el presente apartado se definirán las palabras clave de este estudio (shareholder primacy model, stakeholder model, cortoplacismo societario y los problemas de agencia), lo cual resulta fundamental para entender la relación entre estos conceptos y cómo el cortoplacismo societario es una consecuencia de la dominancia del modelo de primacía de los accionistas, lo que, a su vez, genera problemas de agencia donde los agentes van a satisfacer sus propios intereses, sin considerar el bienestar de los principales.

Conviene preguntarse para quién se administra una compañía y a quién le deben lealtad y cuidado los administradores. ${ }^{3}$ Por un lado, bajo el modelo dominante, el shareholder primacy model o sociocentrismo, las compañías deben administrarse "con el fin de proporcionar el mejor rendimiento posible sobre

3 Frederick Alexander, "Fiduciary duties for conventional corporations enforcing shareholder primacy", en $B e-$ nefit Corporation Law and Governance: Pursuing Profit with Purpose, Oakland, Berrett-Koehler Publishers, 2018, pp. 19-31. 
el capital para los accionistas". ${ }^{4}$ Para los defensores de esa teoría, los asociados son los dueños de acciones o cuotas en las compañías y los directores deben administrarlas para maximizar el valor para sus asociados y en el interés de los mismos. Esta teoría es defendida por importantes autores como Bainbridge, Bebchuk y Friedman. ${ }^{5}$

Las otras partes interesadas o stakeholders, como empleados, consumidores o proveedores, son protegidas por acuerdos contractuales y por otras ramas del derecho, como el laboral, el contractual, el derecho de la competencia y el de consumo. Según los partidarios de esta teoría, estos otros actores no son ni deben ser el foco del derecho de sociedades y de los administradores sociales, los cuales deben tener como norte a los asociados de la compañía por razones de eficiencia y para solucionar el problema de agencia entre accionistas (principal) y administradores (agente). ${ }^{6}$

De lo contrario, si los administradores no los tomaran como el norte de su gestión, los asociados no estarían dispuestos a asumir el riesgo de invertir. Además, si se le asignan al derecho de sociedades otros objetivos, se desvía la atención del propósito principal: maximizar las utilidades para los asociados. Incluso, según Hansmann y Kraakman, el mejor medio para lograr la búsqueda del bienestar social agregado "es hacer que los administradores sociales sean fuertemente responsables ante los intereses de los accionistas y (al menos en términos directos) solo a esos intereses", ${ }^{7}$ ya que si los asociados son los beneficiarios residuales de las sociedades de capital, al incentivar que se genere más valor para ellos, se estaría generando valor para todas las demás partes interesadas.

Un fallo hito en este aspecto fue Dodge contra Ford Motor Co. de la Corte Suprema de Michigan. Dodge ${ }^{8}$ buscaba que se obligara a Ford a pagar mayores dividendos. Ford, por su parte, sostenía que había que balancear el reparto de utilidades con otros objetivos, tales como el aumento del salario de los empleados, la contratación de más empleados, la expansión de la planta y la disminución del precio de los vehículos para beneficiar a los consumidores.

$4 \quad$ Ibid., p. 21.

5 Milton Friedman, "A Friedman doctrine-The Social Responsibility of business is to increase its profits", 13 de septiembre de 1970, en https://www.nytimes.com/1970/09/13/archives/a-friedman-doctrine-the-socialresponsibility-of-business-is-to.html, fecha de consulta: 5 de junio de 2021. Stephen Bainbridge, "In defense of the shareholder wealth maximization norm: A reply to professor Green", en Washington $\mathcal{E}$ Lee Law Review 50 (4) (1993), pp. 1423-1447. Lucian Bebchuk, "The case for increasing shareholder power", en Harvard Law Review 118 (3) (2005), pp. 833-914.

6 Henry Hansmann y Reinier Kraakman, "The end of history for corporate law", en Georgetown Law Journal 89 (2) (2001), pp. 439-468 y 440-441. Empero, Hansmann y Kraakman señalan que los acreedores son una excepción ya que el derecho societario también se ocupa de mitigar los problemas de agencia entre acreedores (principales) y la compañía o los accionistas (agentes), por ejemplo, a través de la desestimación de la personalidad jurídica.

$7 \quad$ Ibid., p. 441.

8 Dodge c. Ford Motor Co., 204 Mich. 459, 170 N.W. 668, 1919. 
La Corte Suprema de Michigan decidió que Ford entregara dividendos adicionales a los accionistas. Considerando que el propósito de una compañía era maximizar las utilidades para sus accionistas, había una negativa arbitraria de Ford a distribuir dividendos. ${ }^{9}$ No podían los directores cambiar el fin de las compañías para administrarlas hacia fines altruistas. Por lo tanto, los deberes fiduciarios se le deben a los accionistas y no a otros grupos de interés:

Una sociedad de capital se organiza y opera principalmente para el beneficio de los accionistas. Los poderes de los directores se utilizarán para tal fin. La discreción de los directores se ejerce en la elección de los medios para lograr ese fin, y no se extiende a un cambio en el fin mismo, a la reducción de las ganancias o a la no distribución de las ganancias entre los accionistas para dedicarlas a otros fines. ${ }^{10}$

Por otro lado, el stakeholder model parte de la premisa de que las sociedades de capital son permitidas por el derecho para cumplir una función social. ${ }^{11}$ Por consiguiente, según autores como Blair y Stout, los administradores tienen una función mediadora entre los diferentes grupos de interés y "no deben actuar como agentes que persiguen sin piedad los intereses de los accionistas a expensas de los empleados, acreedores u otros grupos de interés", sino como "mediadores cuyo trabajo es equilibrar los intereses divergentes" de dichos grupos. ${ }^{12}$

Debe aclararse que los stakeholders o partes interesadas incluyen también a los socios de las compañías, sin embargo, abarcan además otros grupos de interés, como los empleados, proveedores, consumidores, etc. Bajo el stakeholder model "los administradores deben cuidar los intereses de los accionistas y tienen derecho a recibir una compensación por su trabajo. Pero hay otros stakeholders cuyos derechos también deben tenerse en cuenta en el gobierno de una empresa" ${ }^{13}$

$9 \quad$ Idem. En este caso, la Corte Suprema de Michigan no intervino en la decisión de disminuir el precio de los vehículos ni en la expansión de la planta de producción por la aplicación del estándar de la business judgment rule o regla de discrecionalidad. Otro caso del modelo de primacía de los accionistas es el de eBay Domestic Holdings, Inc. c. Newmark, 16 A.3d 1 (Del. Ch. 2010).

10 Idem. "A business corporation is organized and carried on primarily for the profit of the stockholders. The powers of the directors are to be employed for that end. The discretion of directors is to be exercised in the choice of means to attain that end and does not extend to a change in the end itself, to the reduction of profits or to the nondistribution of profits among stockholders in order to devote them to other purposes". (Nota: las traducciones de las citas en inglés son propias).

11 Alexander, "Fiduciary duties for conventional corporations enforcing shareholder primacy", op. cit., p. 24. Lo anterior no significa que el stakeholder model sea el deber ser en todos los sistemas jurídicos y económicos del mundo, ya que su aplicación deberá analizarse caso por caso.

12 Margaret Blair y Lynn Stout, "A team production theory of corporate law", en Virginia Law Review 85 (2) (1999), pp. $247-328$, p. 280 . “... is not to act as agents who ruthlessly pursue shareholders' interests at the expense of employees, creditors, or other team members. Rather, the directors are trustees for the corporation itself-mediating hierarchs whose job is to balance team members' competing interests in a fashion that keeps everyone happy enough that the productive coalition stays together".

13 Alfonso Martínez-Echevarría, "The nature of shareholding and regulating shareholders' duties", en H. Birkmose (ed.), Shareholders' Duties, European Company Law Series vol. 12, Países Bajos, Kluwer Law International BV, 2017, p. 49 ("The managers must take care of the interests of the shareholders and they are entitled to receive compensation for their work. But there are other stakeholders whose rights should also be taken into account in the governance of a company"). Sobre este segundo modelo, también puede verse Michelle Welsh, Peta Spender, Irene Lynch Fannon y Kath Hall, “The end of the ‘End of History for Corporate Law'?", en Australian Journal of Corporate Law 29 (2014), pp. 147-168. 
Recientemente, el World Economic Forum de 2019 abogó por la acogida del stakeholder capitalism, un modelo en el que "las empresas son administradoras de la sociedad, y representan la respuesta más acertada a los desafíos sociales y ambientales de nuestros días" ya que "el capitalismo de accionistas descuidó el hecho de que una empresa es un organismo social, además de uno con fines de lucro". ${ }^{14}$

En igual sentido, Business Roundtable, que desde 1997 ha compartido los principios del modelo de primacía de los accionistas, en el año 2019 emitió una declaración sobre el propósito de las sociedades de capital. Allí, 181 CEO (chief executive officer) se comprometieron a liderar las empresas en beneficio de todas las partes interesadas (stakeholders): clientes, empleados, proveedores, comunidades y accionistas. ${ }^{15}$

Ahora bien, una vez definido el shareholder primacy model y el stakeholder model, resulta fundamental definir el cortoplacismo societario que es una consecuencia del modelo dominante de primacía de los accionistas, según se desarrollará a lo largo del presente escrito. El cortoplacismo en derecho de sociedades es definido por Duruigbo como "el fenómeno por el cual algunos administradores sociales, respondiendo a la presión de los inversionistas o actuando para reforzar su propia posición, centran su atención y emplean sus energías para lograr la rentabilidad a corto plazo, renunciando prácticamente a consideraciones de largo plazo". ${ }^{16}$

Para Mitchell, "una causa importante de este enfoque a corto plazo es la visión sociocentrista impuesta a la administración por el derecho corporativo tradicional" ${ }_{1}^{17}$ que exige a los administradores rentabilidad actual e incremento en el precio de la acción y, por esto, su solución es transformar la administración en un cuerpo mediador entre los diferentes grupos de interés. Así, para la autora, ampliar los deberes de los administradores no implica su irresponsabilidad, sino que los empodera para cumplir los objetivos de la organización. ${ }^{18}$

14 World Economic Forum, “¿Qué tipo de capitalismo queremos?”, 2 de diciembre de 2019, en https:// es.weforum.org/agenda/2019/12/que-tipo-de-capitalismo-queremos/, fecha de consulta: 12 de septiembre de 2020. World Economic Forum, "Manifiesto de Davos 2020: el propósito universal de las empresas en la Cuarta Revolución Industrial”, 2 de diciembre de 2019, en https://es.weforum.org/agenda/2019/12/manifiesto-dedavos-2020- el-proposito-universal-de-las-empresas-en-la-cuarta-revolucion-industrial/, fecha de consulta: 12 de septiembre de 2020.

15 Business Roundtable, "Business Roundtable redefines the purpose of a corporation to promote 'An economy that serves all americans"”, 19 de agosto de 2019, en https://www.businessroundtable.org/business-roundtable-redefines-the-purpose-of-a-corporation-to-promote-an-economy-that-serves-all-americans, fecha de consulta: 12 de septiembre de 2020.

16 Emeka Duruigbo, "Tackling shareholder short-termism and managerial myopia”, en Kentucky Law Journal 100 (3) (2011-2012), pp. 531-584, p. 531 ("Short-termism denotes the phenomenon by which some corporate managers, responding to pressure from investors or acting to bolster their own position, advert their attention and

17 Lawrence Mitchell, "A critical look at corporate governance", en Vanderbilt Law Review 45 (5) (1992), pp. 12631318, p. 1272. 
El sociocentrismo podría generar incentivos para que los administradores, al actuar racionalmente y cumplir el deber de maximizar el valor para los accionistas, creen externalidades negativas y externalicen los costos del sociocentrismo, "ya sea expropiando directamente la riqueza de otros grupos de interés para beneficiar a los accionistas, o imponiendo los costos de aumentar las ganancias de los accionistas a otros grupos de interés".${ }^{19}$ Asimismo, el sociocentrismo podría incentivar a los administradores "a concentrarse en el desempeño a corto plazo para asegurar su propia compensación". ${ }^{20}$

Como lo afirma Leo E. Strine, Jr., quien fue presidente de la Corte Suprema de Delaware:

... debemos reconocer que los administradores son cada vez más vulnerables a la presión de los inversores activistas y grupos de accionistas con objetivos a corto plazo y que esta presión puede conducir lógicamente a estrategias que sacrifiquen el rendimiento a largo plazo por la riqueza de los accionistas a corto plazo [...] Si creemos que otros sectores deben recibir más protección dentro del propio derecho de sociedades, luego deben adoptarse leyes que les otorguen derechos exigibles que puedan ejercer [...] entonces lo que se requiere es una reactivación de la regulación de externalidades efectiva que brinde a estos intereses una protección más efectiva y oportuna. ${ }^{21}$

El cortoplacismo societario es un "efecto tóxico" del modelo de primacía de los asociados que se ve agravado por la presencia de inversionistas institucionales que gozan de más influencia en los administradores sociales que los inversionistas individuales, especialmente los fondos de inversión y los hedge funds que son conocidos por "tener acciones típicamente por solo uno o dos años" y se enfocan en altos rendimientos a corto plazo. ${ }^{22}$ Adicionalmente, la naturaleza cortoplacista de inversiones de derivados como las opciones y los futuros contribuye a "cambiar el enfoque de los mercados de estrategias a largo plazo a estrategias a corto plazo"..$^{23}$

Enfocarse en una visión a corto plazo es contraproducente para el crecimiento económico de la sociedad a largo plazo, la responsabilidad social empresarial y la sostenibilidad ambiental. ${ }^{24}$ Además, la falta de atención a estos objetivos

$19 \quad$ Ibid., p. 1288.

20 Thomas Hazen, "The short-term/long-term dichotomy and investment theory: Implications for securities market regulation and for corporate law", en North Carolina Law Review 70 (1) (1991), pp. 137-207, p. 181.

21 Leo Strine, "The dangers of denial: The need for a clear-eyed understanding of the power and accountability structure established by the Delaware General Corporation Law", en Wake Forest Law Review 50 (2015).

22 Lynn Stout, "The toxic side effects of shareholder primacy", en University of Pennsylvania Law Review 161 (7) (2013), pp. 2003-2023. Aspen Institute Business \& Society Program, Overcoming Short-termism: A Call for a More Responsible Approach to Investment and Business Management, 16 de septiembre de 2009, en https://www. aspeninstitute.org/publications/overcoming-short-termism-call-more-responsible-approach-investment-business-management/c, fecha de consulta: 12 de septiembre de 2020.

23 Hazen, "The short-term/long-term dichotomy and investment theory: Implications for securities market regulation and for corporate law", op. cit., p. 163.

24 Frederick Beale y Mario Fernando, "Short-termism and genuineness in environmental initiatives: a comparative case study of two oil companies", en European Management Journal 27 (1) (2009), pp. 26-35, p. 27. 
de largo plazo puede llevar a daños reputacionales que afectan el valor de la compañía y el precio al que se negocian las acciones. ${ }^{25}$

Finalmente, el problema de agencia "corresponde a las dificultades que surgen cuando el bienestar de una de las partes denominada el mandante (principal), depende de las acciones adelantadas por un tercero, denominado el mandatario o agente (agent)" ${ }^{26}$ No obstante, debe resaltarse que no toda relación de agencia implica delegación o encargo de una gestión, por lo que no siempre puede hablarse de mandante y mandatario; por ejemplo, en el caso de los grupos de interés no opera una delegación al agente. Por tal razón, el problema de agencia puede ser definido de forma más general como las dificultades que se generan cuando el bienestar de una persona denominada el principal depende de la conducta de otra llamada el agente.

La función del derecho societario consiste en mitigar los problemas de agencia que surgen entre los diferentes actores, y reducir los costos de agencia y la discrecionalidad de los agentes para que estos actúen en beneficio del principal. Al existir asimetría de la información, el agente tenderá a actuar de forma oportunista, anteponiendo su propio interés en detrimento del principal. Así, surgen tres problemas de agencia generales según Kraakman, Hansman y Armour (principal-agente): accionistas-administrador, accionistas minoritariosaccionistas mayoritarios y terceros interesados-compañía. ${ }^{27}$

De los problemas de agencia generales pueden derivarse otros como el de los accionistas minoritarios que también pueden actuar como agentes de los accionistas mayoritarios (principales) cuando los primeros tengan derecho de vetar alguna decisión. De igual forma, como se desarrollará en este trabajo, podrían los minoritarios -en una visión cortoplacista- presionar a los mayoritarios y exigir el reparto de utilidades sin considerar el mejor interés de la compañía a largo plazo y la necesidad de hacer reservas.

Asimismo, los administradores, privilegiando el corto plazo y para asegurar su permanencia en el cargo o su bonificación, podrían anteponer sus propios intereses a los de la compañía, y sacrificar el bienestar de la empresa a largo plazo. Por ejemplo, los administradores podrían actuar para generar más utilidades en el presente para los accionistas, aunque sea a costa de la capacidad para generar utilidades en el futuro, como en el caso de Valeant Pharmaceuticals International Inc. sobre el que se profundizará posteriormente. 2017, p. 29. 
En la tabla 1 se resumen los distintos tipos de problema de agencia que podrían presentarse.

Tabla 1. Versión ampliada de los problemas de agencia en el derecho societario

\begin{tabular}{|c|c|}
\hline Principal & Agente \\
\hline Accionistas & Administrador \\
\hline Accionistas minoritarios & Accionistas mayoritarios \\
\hline Accionistas mayoritarios & Accionistas minoritarios \\
\hline Otros interesados & Compañía \\
\hline Compañía & Accionistas \\
\hline Compañía & Administradores \\
\hline
\end{tabular}

Fuente: elaboración propia.

Para reducir los costos de agencia, el derecho de sociedades crea estrategias regulatorias y estrategias de gobernanza. Las primeras dictan los términos que gobiernan la relación principal-agente, restringen directamente el comportamiento del agente y dependen para su eficacia de una autoridad externa que determine si el agente cumplió o no con sus obligaciones. Las segundas buscan facilitar el control de los principales sobre el comportamiento de los agentes y dependen de la habilidad del principal de ejercer los derechos de controlar al agente. ${ }^{28}$

Los autores Kraakman, Hansman y Armour dividen las estrategias legales en ex ante, antes de que el agente actúe, o ex post, para juzgar posteriormente las acciones del agente. Se encuentran así las restricciones del agente a través de las obligaciones de hacer o no hacer (ex ante), o a través de estándares de conducta como la buena fe, los deberes fiduciarios de los administradores, la business judgment rule o el entire fairness cuyo cumplimiento o no por parte del agente es determinado por una autoridad (ex post $)^{29}$ (tabla 2).

Adicionalmente, se encuentran regulaciones para los términos en que el principal contrata con el agente (ex ante), por ejemplo, exigencias de revelación de información y también oportunidades de salida para el principal (ex post), tales como la venta de su participación en la compañía o el derecho de retiro para escapar de los agentes oportunistas. ${ }^{30}$ Igualmente, para alinear los incentivos se puede hacer uso de terceros independientes (ex ante) como directores, comi-

28 Kraakman, Hansman y Armour, "Agency problems and legal strategies", op. cit., pp. 31 y 32. 
tés o auditores independientes, o también utilizar estrategias de recompensa para el agente como el pago por rendimiento o las opciones de acciones para los administradores (ex post). ${ }^{31}$

Además, teniendo en cuenta la administración delegada en las sociedades, se puede regular la selección de los administradores (ex ante), bien sea mediante la representación proporcional en la junta directiva o por el "voto acumulativo y la asignación de curules en los órganos directivos a los accionistas minoritarios", ${ }^{32}$ así como la remoción de los administradores a través de la convocatoria a una asamblea de accionistas donde se nombre una nueva junta directiva (ex post).

Finalmente, los derechos de decisión otorgan poder al principal para intervenir en la dirección de la empresa, dándole el poder de autorizar o ratificar las decisiones del agente, por ejemplo, al necesitar la autorización del principal para celebrar operaciones viciadas por conflicto de interés, bajo una revelación completa de información al principal (ex ante). También existen ciertas decisiones que estatutariamente solo pueden ser aprobadas por la asamblea de accionistas con mayoría calificada, en las cuales la minoría puede tener derecho de veto o exigir a los jueces negar la validez de decisiones tomadas sin cumplir los derechos de decisión de los directores (ex post). ${ }^{33}$

Tabla 2. Estrategias legales para la protección de principales según Kraakman, Hansman y Armour

\begin{tabular}{|c|c|c|c|c|c|}
\hline & $\begin{array}{c}\text { Restricciones } \\
\text { al agente }\end{array}$ & $\begin{array}{c}\text { Condiciones } \\
\text { de afiliación }\end{array}$ & $\begin{array}{c}\text { Alineación de } \\
\text { incentivos }\end{array}$ & $\begin{array}{c}\text { Derechos de } \\
\text { nombramiento }\end{array}$ & $\begin{array}{c}\text { Derechos de } \\
\text { decisión }\end{array}$ \\
\hline Ex ante & Reglas & Entrada & $\begin{array}{c}\text { Terceros } \\
\text { independientes }\end{array}$ & Selección & Inicio \\
\hline Ex post & Estándares & Salida & Recompensa & Remoción & Veto \\
\hline
\end{tabular}

Fuente: Kraakman, Hansman y Armour, "Agency problems and legal strategies", op. cit., p. 32.

Una vez desarrolladas las precisiones conceptuales de shareholder primacy model, stakeholder model, cortoplacismo societario y los problemas de agencia, en el tercer aparte de este escrito se verán estos conceptos en el caso de Estados Unidos. En este país, el modelo de primacía de los accionistas es dominante, lo que crea una tendencia al cortoplacismo societario y aumenta los problemas de agencia, ya que el objetivo de maximizar utilidades para los accionistas en muchos casos se hace sin considerar las externalidades que esto podría

$474 \quad 32 \quad$ Reyes Villamizar, Análisis económico del derecho de sociedades, op. cit., pp. 59 y 60. mour, Luca Enriques, Henry Hansmann y Reinier Kraakman, “The basic governance structure: The interests of shareholders as a class", en European Corporate Governance Institute (ECGI), Law Working Paper (337) (2017). 
generar en algunos casos, lo que impone a los otros stakeholders los costos de incrementar las ganancias de los asociados.

\section{Estados Unidos: el modelo de primacía de los accionistas y el cortoplacismo societario en los casos Dodge contra Ford, Valeant y Enron}

Para desarrollar la aplicación de los conceptos anteriores, particularmente la forma como opera el shareholder primacy model en Estados Unidos, y cómo este ha impactado de manera significativa el surgimiento de diferentes problemas de agencia, se estudiarán tres casos de gran relevancia: Dodge contra Ford, Valeant Pharmaceuticals International Inc. y Enron. A partir de estos casos se evidencia de forma clara cómo el modelo de primacía de los accionistas en Estados Unidos, que está enfocado en cumplir y perseguir los intereses de los accionistas, afecta en gran medida la satisfacción de los intereses de otras partes interesadas como agentes (stakeholders), cuyo bienestar se ve afectado por las decisiones societarias del principal.

De esta forma, se mostrará cómo este modelo, que aboga por la obtención de lucro para los accionistas en el corto plazo, no tiene en cuenta que las decisiones que se toman para cumplir ese objetivo pueden impactar de forma negativa a otras partes interesadas, e incluso repercutir a largo plazo en el bienestar de los mismos accionistas, los administradores o la compañía. Es importante aclarar que se acude a casos en Estados Unidos para ilustrar el tema, pero no se pretende simplificar o explicar en su totalidad el sistema de derecho societario de este país, el cual está regulado en cada uno de los Estados.

Las sociedades abiertas de Estados Unidos se han caracterizado por tener tradicionalmente un modelo de capital disperso que influye directamente en la división que existe entre la propiedad de la compañía (asociados) y quienes detentan su control (administradores) ${ }^{34} \mathrm{y}$, con ello, el poco activismo de los

34 Adolf Berle y Gardiner Means, The Modern Corporation \& Private Property, 2 ed., New York, Routledge Taylor \& Francis Group, 1932, p. 49. En el estudio de Berle y Means se observa que solo 20 de las 144 empresas más grandes de Estados Unidos tenía menos de 5.000 accionistas, mientras que 71 de 144 empresas tenían más de 20.000 socios. Tabla 3. 144 de las 200 compañías más grandes de Estados Unidos distribuidas según el número de accionistas:

\begin{tabular}{|c|c|c|c|c|}
\hline & Railroads & Public Utilities & Industrials & Total \\
\hline Under 5,000 & 10 & 5 & 5 & 20 \\
\hline $5,000-19,999$ & 16 & 11 & 26 & 53 \\
\hline $20,000-49,999$ & 8 & 5 & 26 & 39 \\
\hline $50,000-99,999$ & 3 & 10 & 9 & 22 \\
\hline $100,000-199,999$ & 1 & 3 & 3 & 3 \\
\hline $200,000-500,000$ & & 3 & & 144 \\
\hline Total & 38 & 37 & 69 & (2) \\
\hline
\end{tabular}

Fuente: Adolf Berle y Gardiner Means, The Modern Corporation \& Private Property, 2 ed., New York, Routledge Taylor \& Francis Group, 1932, p. 49. 
asociados en la administración de la compañía, contrario a lo que ocurre en países donde prima el modelo de capital concentrado. ${ }^{35}$

Al respecto, según un estudio realizado por La Porta a partir de la estructura de la propiedad de las compañías más prósperas de 27 países diferentes por su ingreso per cápita y la protección que ofrece la regulación a sus asociados, "una comparación de países con buena y deficiente protección a los accionistas muestra que las compañías de capital disperso son más comunes en países con buena protección". ${ }^{36}$

Así, en la comparación realizada entre países con buena y deficiente protección a los asociados, se evidenció que, generalmente, "en países con una buena protección, las compañías de capital disperso representan el $48 \%$ y en países con una protección más deficiente, este tipo de compañías solo representa el $27 \%{ }^{\prime \prime} .^{37}$

Por lo tanto, según el estudio de La Porta, la estructura tradicional corporativa de capital disperso en Estados Unidos obedece, en gran medida, a la importante protección que existe para los asociados de estas compañías dado que, de los 27 países analizados, se llegó a la conclusión de que 12 de estos países ofrecen una mejor protección a los asociados y, en esa medida, varía la estructura corporativa de las compañías. Sin embargo, esta protección no elimina por completo los problemas de agencia que se pueden presentar entre los asociados y quienes ejercen la administración de la sociedad, así como los que surgen entre la sociedad y otros grupos de interés, sobre todo porque, a medida que se fracciona más el capital social en este tipo de compañías, aumentan los costos de coordinación y de vigilancia de los asociados en la gestión de la sociedad e inmediatamente aumenta la discrecionalidad de la actuación de los administradores.

De esta forma, resulta fundamental lograr que los administradores (agente) actúen en interés de los asociados (principal), dejando de lado su propio interés. Esto se puede explicar desde una de las corrientes del análisis económico del derecho más tradicional, que es la Escuela de Chicago. En términos de Posner, "el hombre que actúa racionalmente siempre busca la forma de aumentar sus fines y satisfacciones y, modificará su comportamiento en la medida que se presenten circunstancias a partir de las cuales podría aumentar sus satisfacciones" ${ }^{38}$ En el caso de las sociedades de capital, los administradores detentan la capacidad de dirigir el rumbo de la compañía y, cuando el

35 John Coffee, "The future as history: The prospects for global convergence in corporate governance and its implications", en Northwestern University Law Review 93 (3) (1999), p. 641.

36 Rafael La Porta, Florencio López de Silanes y Andrei Shleifer, "Corporate ownership around the world", en The Journal of Finance 54 (2) (1999), p. 496 ("A comparison of countries with good and poor shareholder protection shows that widely held firms are more common in countries with good protection").

37 Idem.

38 Richard Posner, El análisis económico del derecho, México, Fondo de la Cultura Económica, 7 ed., 2007, p. 25. 
capital es altamente disperso, el costo de vigilancia de los accionistas hacia el administrador aumenta.

Teniendo en cuenta lo anterior, a continuación se explicará cómo la racionalidad de los agentes de maximizar su propio beneficio influye en los problemas de agencia que se pueden presentar en las compañías de capital disperso en Estados Unidos, y cómo el shareholder primacy model lleva a que los costos de aumentar las utilidades de los accionistas, como objetivo principal de las sociedades de capital, se transfieran a otros grupos de interés, con la posibilidad de crear externalidades negativas según el caso.

En el caso Dodge contra Ford Motor Co.,${ }^{39}$ al que se hizo referencia en las precisiones conceptuales, Henry Ford detentaba la mayoría de la participación accionaria en Ford Motor Company y tomó, entre otras, la decisión de disminuir el costo de los vehículos que la compañía tenía en venta en el mercado y de aumentar el salario de sus empleados. De esta manera, los dividendos por repartirse entre los accionistas al final del ejercicio sufrieron una reducción y esto generó inconformidad en los hermanos Dodge, accionistas minoritarios, quienes consideraron que las medidas adoptadas por Henry Ford estaban encaminadas a repartir dividendos entre los empleados de la compañía. ${ }^{40}$

Por la participación mayoritaria que tenía Henry Ford en la compañía, era claro que tenía la capacidad de influir de manera significativa en las decisiones y, especialmente, en lo relativo a los dividendos, y solo así es que pudo influir en la determinación de repartir dividendos (a través de aumentos salariales) entre sus empleados. ${ }^{41}$ Esto no solo generó un claro ejemplo de problema de agencia entre administradores y accionistas, y entre accionistas mayoritarios y minoritarios, sino que, en caso de proteger los intereses de los hermanos Dodge, nacería otro problema de agencia entre la sociedad propiamente dicha y sus empleados.

Durante el contrainterrogatorio a Henry Ford, ante la pregunta de para qué se había creado la compañía si no era para generar utilidades, el señor Ford respondió que para "generar tanto bienestar como fuera posible, a todas las personas y en todas partes e, incidentalmente, para hacer dinero". ${ }^{42}$ No obstante, en este caso, la Corte Suprema de Michigan optó por aplicar el modelo de primacía de los accionistas, bajo el supuesto de que los administradores

\footnotetext{
39 Dodge c. Ford Motor Co., op. cit.

40 Idem.

41 El Tribunal Supremo de Michigan en el caso de Hunter c. Robert, Throp \& Co., 83 Mich 63, 71, 47 N. W. 131 reconoció que "es un principio de derecho bien conocido, que los administradores de una sociedad de capital y solo ellos, tienen el poder de declarar un dividendo de las utilidades de la sociedad de capital y determinar su monto" ("It is a well-recognized principle of law that the directors of a corporation, and they alone, have the power to declare a dividend of the earnings of a corporation, and to determine its amount").

42 Todd Henderson, "Everything old is new again: Lessons from Dodge v. Ford Motor Company", en John M. Olin Program in Law and Economics, Working Paper 373 (2007), pp. 22 y 23.
} 
sociales deben encaminar sus acciones a lograr mayores beneficios para sus asociados, y el poder de discrecionalidad con el que cuentan a partir de la relación de agencia existente entre ellos y los asociados no los faculta para alejarse de ese objetivo y dedicar las compañías a otros fines.

De esta manera, a pesar de que Henry Ford actuó, en términos de Posner, persiguiendo su propio interés el cual estaba materializado en un fin altruista y que beneficiaba a los demás stakeholders, se alejó de perseguir el mejor interés de los demás accionistas quienes verían reducidos sus dividendos al final del ejercicio. Aunque la respuesta de la Corte Suprema de Michigan al aplicar el modelo de primacía de los accionistas tuvo como consecuencia directa la mitigación del problema de agencia que había surgido entre los administradores (agente) y los accionistas (principal), y entre los accionistas mayoritarios (agente) y los minoritarios (principal), desconoció el impacto que ello generaría principalmente en los empleados que se habían visto beneficiados por el aumento de ingresos de la sociedad.

Este es un ejemplo que evidencia cómo el shareholder primacy model ha sido utilizado para solucionar un problema de agencia muy común. Sin embargo, refleja cómo la consecuencia directa de esta aplicación puede desencadenar en la existencia de otro problema de agencia entre la sociedad y otros grupos de interés.

Otro caso importante, que refleja la manera como los administradores privilegian la obtención de ganancias para los accionistas en perjuicio de otros grupos de interés es el de Valeant Pharmaceuticals International Inc., que cambió su nombre a Bauch Health Companies Inc. ${ }^{43}$ Esta compañía es una de las más importantes y grandes farmacéuticas canadienses, se encuentra registrada en la Securities and Exchange Commission de Estados Unidos (SEC), está incorporada en el Estado de Nueva Jersey ${ }^{44}$ y negocia sus acciones en el New York Stock Exchange.

Valeant, en lugar de destinar un porcentaje de sus ganancias para invertir en el desarrollo y la investigación de nuevos de medicamentos, como la mayoría de las farmacéuticas lo hacen, encaminó su práctica a adquirir sociedades farmacéuticas que ya habían descubierto y patentado nuevos medicamentos fundamentales para pacientes con enfermedades particulares para, posteriormente, incrementar el valor de venta al público hasta en un $700 \% .{ }^{45}$ Los

43 Alex Gibney y Brian McGinn, “Dirty Money: Short selling and pharmaceuticals”, 2018, en www.netflix.com, fecha de consulta: 12 de septiembre de 2020.

44 U.S. Security and Exchange Comission, "SEC Registration: Bausch Health Companies Inc.", SEC CIK No. 0000885590, en https://sec.report/CIK/0000885590, fecha de consulta: 19 de septiembre de 2020.

47845 Gibney y McGinn, "Dirty Money: Short selling and pharmaceuticals", op. cit. Sobre el caso Valeant y el modelo de primacía de los accionistas, véase Joseph Bower y Lynn Paine, "The error at the heart of corporate leadership", en Harvard Business Review, en https://hbr.org/2017/05/managing-for-the-long-term, fecha de consulta: 20 de septiembre de 2020; Louise Lee, "It's time to value stakeholders over shareholders", en Stan- 
consumidores se veían obligados a adquirir medicinas a precios exorbitantes por falta de genéricos y las aseguradoras debían cubrir los altos precios de los medicamentos lo que, en última instancia, conllevaba cobrar primas de seguro médico más altas, costos que se imponían a terceros para generar mayores utilidades para los accionistas de Valeant.

Si bien este modelo de negocio que adoptó Valeant generaba en el corto plazo mayores ingresos por ventas a la compañía, simultáneamente, se vio inmiscuida en diferentes escándalos de corrupción revelados principalmente por Citron Research. Citron Research puso de presente que Valeant emitía facturas, para recibir pagos de compañías que eran de su propiedad, por servicios que en realidad Valeant no prestaba e incluso una de esas compañías, denominada Philidor RX, no tenía licencia de funcionamiento para operar como farmacia, pero emitía prescripciones médicas que posteriormente se cobraban a las aseguradoras de seguros médicos y, así, no solo se estafaba a las compañías de seguros, sino que se obtenían importantes sumas de dinero. ${ }^{46}$ Como Valeant cotizaba en Wall Street, sus acciones empezaron a desplomarse significativamente, lo que generó grandes pérdidas para sus accionistas. ${ }^{47}$

En este caso es claro que las decisiones de los administradores para encaminar el modelo de negocio de Valeant reflejaron la aplicación del modelo de primacía de los accionistas y fueron un claro ejemplo de cortoplacismo societario. En Valeant, los administradores actuaron para generar las mayores utilidades a los accionistas en periodos de tiempo muy cortos, sin pensar en el futuro sostenimiento de la compañía y trasladando los costos de incrementar las ganancias de los socios a los stakeholders como los pacientes y consumidores de medicamentos, así como a todos los usuarios de seguros médicos a quienes las aseguradoras aumentaban las primas para compensar por los pagos de medicamentos a precios excesivos.

Al respecto, algunos autores consideran que los recortes en investigación y desarrollo son comunes en compañías donde los accionistas dominantes son "instituciones transitorias, es decir, aquellas con una alta rotación del portafolio y estrategias de inversión muy sólidas" ${ }^{48}$ Además, caracterizan como "comportamiento de inversión miope" las decisiones de administradores de compañías que, como Valeant, se enfrentan al dilema entre cumplir los objetivos de obtener ganancias y mantener la inversión en investigación y desarrollo

ford Business, 4 de mayo de 2018, en https://www.gsb.stanford.edu/insights/its-time-value-stakeholders-overshareholders, fecha de consulta: 20 de septiembre de 2020.

46 Citron Research, "Why a congressional subpoena to valeant about price gouging on drugs should be granted", 28 de septiembre de 2015, en https://citronresearch.com/wp-content/uploads/2015/09/valeant-part-1-final. pdf, fecha de consulta: 20 de septiembre de 2020. Citron Research, "Valeant: Could this be the Pharmaceutical Enron?", 21 de octubre de 2015, en https://citronresearch.com/wp-content/uploads/2015/10/Valeant-Philadorand-RandO-final-a.pdf, fecha de consulta: 20 de septiembre de 2020.

47 Gibney y McGinn, "Dirty Money: Short selling and pharmaceuticals", op. cit.

48 Duruigbo, "Tackling shareholder short-termism and managerial myopia", op. cit., p. 542. 
ya que, después de todo, esto último es lo que hará que la compañía pueda crecer a largo plazo. ${ }^{49}$

Adicionalmente, Duruigbo señala que "una encuesta realizada a más de 400 ejecutivos financieros reveló que más del 80 \% de los encuestados, reducirían discrecionalmente el gasto en áreas como investigación y desarrollo, publicidad, mantenimiento y contratación para cumplir con el objetivo de obtener más ganancias a corto plazo". ${ }^{50}$ Por otro lado, el 50 \% respondió que postergaría el desarrollo de nuevos proyectos, incluso si esto implica sacrificar creación de valor, lo que demuestra, nuevamente, que el corto plazo de nuevo prima sobre el largo plazo para aumentar las ganancias de los accionistas. ${ }^{51}$

\section{Según el Instituto Aspen,}

Los administradores de activos que se basan en un enfoque de ganancias comerciales a corto plazo, tienen pocas razones para preocuparse por el desempeño corporativo a largo plazo. De esta manera, resulta poco probable que ejerzan un papel positivo en la promoción de políticas corporativas, incluyendo políticas de gobierno corporativo que podrían resultar apropiadas y que son beneficiosas a largo plazo. ${ }^{52}$

\section{Además, algunos autores sostienen que}

... un enfoque excesivo en el corto plazo genera una mala asignación de activos por parte de los administradores corporativos, conduce a una volatilidad dañina en los mercados financieros e impone una carga sobre la sociedad para canalizar los recursos productivos hacia la reparación ambiental y el daño social ocasionado por la búsqueda desenfrenada de ganancias. ${ }^{53}$

Los administradores, e incluso los mismos accionistas, podrían tener en cuenta factores a largo plazo como, por ejemplo, el impacto medioambiental, social o reputacional de alguna decisión que le está generando a la compañía un in-

49 Brian Bushee, "The influence of Institutional Investors on Myopic R\&D Investments Behavior", en The Accounting Review, 73 (1998), pp. 305-306 en Duruigbo, "Tackling shareholder short-termism and managerial myopia", op. cit.

50 Duruigbo, "Tackling shareholder short-termism and managerial myopia", op. cit., p. 542. Kurt Schacht, "Breaking the short-term cycle", en Fourth Annual Director's Institute on Corporate Governance (2006), pp. 583-591. Sobre el cortoplacismo societario en la industria de la biotecnología puede verse al profesor del Harvard Business School Bill George, "Another view: Can biotech survive icahn", 3 de junio de 2010, en https://www.billgeorge.org/page/nyt-dealbook-another-view-can-biotech-survive-icahn/, fecha de consulta: 13 de septiembre de 2020.

51 Duruigbo, "Tackling shareholder short-termism and managerial myopia", op. cit., p. 542; George Dent, "The essential unity of shareholders and the myth of investor short-termism", en Delaware Journal of Corporate Law 35 (1) (2010), pp. 126-128.

52 Aspen Institute Business \& Society Program, “Overcoming short-termism: A call for a more responsible approach to investment and business management", 16 de septiembre de 2009, en https://www.aspeninstitute. org/publications/overcoming-short-termism-call-more-responsible-approach-investment-business-management/, fecha de consulta: 12 de septiembre de 2020.

48053 Duruigbo, "Tackling shareholder short-termism and managerial myopia", op. cit., p. 534 ("One observer contends that an excessive focus on the short-term engenders misallocation of assets by corporate managers, leads to harmful volatility in the financial markets and imposes a burden on society to channel productive resources into repairing environmental and social damage occasioned by unbridled quest for profits"). 
greso importante en el corto plazo, sin que necesariamente estos factores sean una preocupación o interés fundamental para la empresa. ${ }^{54}$

En efecto, optar por ignorar estos factores en última instancia "puede representar un peligro significativo a largo plazo para las compañías", 55 por ejemplo, la pérdida de valor de las acciones (como le sucedió a Valeant) por el impacto reputacional que generó el conocimiento público de sus transacciones fraudulentas. Lo irónico en el caso de Valeant es que la supervivencia actual de la compañía depende de mantener altos los precios de los medicamentos, a costa de los demás stakeholders, ya que si los disminuyera se quebraría. ${ }^{56}$

Aunque con la toma de decisiones a corto plazo se pretenda buscar la maximización de los beneficios para los accionistas (modelo de primacía de los accionistas) y así mitigar el problema de agencia entre estos y los administradores, este objetivo no necesariamente resulta protegido con tales decisiones ya que, en la mayoría de los casos, no comprenden el impacto futuro que se puede generar a los mismos accionistas. De esta forma, los administradores deberían identificar cuáles son los intereses de los accionistas a largo plazo y perseguirlos. ${ }^{57}$

Asimismo, las decisiones corporativas deberían comprender un nuevo componente que radica en tener en cuenta el beneficio o la reducción de impactos de sus decisiones en los otros stakeholders, abogando por el stakeholders model. El cortoplacismo societario y el afán por obtener ganancias para los accionistas está poniendo en riesgo a los demás stakeholders, a las compañías y a los accionistas. ${ }^{58}$

Tanto Dodge contra Ford como Valeant son un ejemplo de que la mitigación de los problemas de agencia (mayoritarios-minoritarios y administradores-accionistas) a partir de la aplicación del modelo de primacía de los accionistas podría llevar al cortoplacismo a la hora de tomar decisiones de gestión en el rumbo de la sociedad y a externalidades negativas para otros stakeholders. Esta situación puede llevar a que las compañías en el largo plazo se encuentren -como Valeant está actualmente- perdiendo cada día más valor, aunque sus decisiones de corto plazo hubiesen buscado el mayor beneficio de sus accionistas.

\footnotetext{
Idem.

55 Marleen O'Connor, “Organized labor as shareholder activist: Building coalitions to promote worker capitalism", en University of Richmond Law Review 31 (5) (1997), pp. 1345-1398, p. 1375.

56 Gibney y McGinn, "Dirty Money: Short selling and pharmaceuticals", op. cit.

57 Justin Lahart, "Wrong way? Street signs point to speed", en The Wall Street Journal, 26 de febrero de 2007, en https://www.wsj.com/articles/SB117244638061618757, fecha de consulta: 13 de septiembre de 2020.

58 Otro caso interesante es el escándalo de Volkswagen que, a través de un software para falsear las emisiones de gases, afectó durante años al medio ambiente, lo que generó externalidades negativas a cambio de mayores ingresos para la compañía y, en consecuencia, un incremento en las ganancias para los accionistas. Lo anterior afectó a largo plazo la reputación de la compañía y, por lo tanto, a los accionistas (The Guardian, "The Volkswagen emissions scandal explained", 23 de septiembre de 2015, en https://www.theguardian.com/ business/ng-interactive/2015/sep/23/volkswagen-emissions-scandal-explained-diesel-cars, fecha de consulta: 20 de septiembre de 2020).
} 
Ello podría obedecer a que, en contextos de capital disperso, la capacidad de controlar la conducta de los administradores por parte de los asociados es menor por los altos costos de coordinación y vigilancia. Adicionalmente, podría deberse al cortoplacismo de los mismos accionistas que se regocijan al ver cómo aumenta el precio de mercado de la acción, sin importar a qué costo se está haciendo y a costa de quién o de qué.

Por lo tanto, tanto Ford como Valeant son un ejemplo de que la mitigación de los problemas de agencia (mayoritarios-minoritarios y administradoresaccionistas) a partir de la aplicación del modelo de primacía de los accionistas crea, necesariamente, otro problema de agencia entre la compañía y los otros grupos de interés.

Este problema de agencia (compañía-otras partes interesadas) estuvo presente en uno de los escándalos financieros más grandes en Estados Unidos protagonizado por Enron, una compañía dedicada a la transmisión de energía eléctrica, con un gran portafolio de servicios. ${ }^{59}$ Además, fue catalogada en varias oportunidades como una de las empresas más innovadoras de Estados Unidos y como una de las mejores empleadoras de dicho país caracterizada por su intención de generar bienestar a sus empleados. ${ }^{60}$

Sin embargo, su reputación comenzó a declinar cuando se dieron a conocer los rumores sobre la existencia de sobornos para resultar adjudicatarios de contratos que les generarían mayores ganancias en un corto plazo y, particularmente, por las diferentes estrategias fraudulentas avaladas por su firma de contabilidad que maquillaba los pasivos como activos en los estados financieros después de culminada una transacción determinada. ${ }^{61}$ En consecuencia, al ser una compañía que cotizaba en la bolsa de valores, la afectación de su reputación y el ocultamiento de su valor real produjeron que el valor de la acción también decayera.

Enron, bajo las actuaciones de sus administradores Ken Lay y Jeff Skilling, persiguió el máximo valor para sus accionistas a través de un plan de negocios que era plausible e innovador en el corto plazo por medio de la oferta de diferentes servicios, lo que generó un aumento de las cifras de la compañía en el corto plazo. ${ }^{62}$ Sin embargo, esa persecución del mayor valor inmediato para sus accionistas provocó que la compañía se volviera propensa al riesgo y actuara dentro del margen de ese riesgo, sobre todo por su práctica reiterada consistente en el ocultamiento de información crítica.

$59 \quad$ Alex Gibney, "Enron: The smartest guys in the room", en Amazon Prime Video, 2005, en www.primevideo. com, fecha de consulta: 5 de junio de 2021.

60 Diario La Vanguardia, "Enron: el mayor escándalo financiero de la historia, tan grande como olvidado", 2 de diciembre de 2016, en https://www.lavanguardia.com/economia/20161202/412319658496/enron-quiebraescandalo.html, fecha de consulta: 5 de junio de 2021.

61 Gibney, "Enron: The smartest guys in the room", op. cit.

62 Idem. 
Con las decisiones a corto plazo que tomaron los administradores en este caso, se materializaron dos problemas de agencia. El primero relacionado con la disminución en el bienestar de los empleados y el de sus acreedores (stakeholders), pues ambos grupos de interés se encontraban en una compañía que empezó a perseguir desenfrenadamente $y$, a toda costa, diferentes formas de crecimiento, lo que desdibujó el ambiente de bienestar que se había creado para estos grupos de interés y por los cuales la empresa había sido reconocida al inicio de su operación. Así, los costos del cortoplacismo se trasladaron a los millones de empleados de la compañía quienes, en su mayoría, perdieron sus empleos. ${ }^{63}$

El segundo problema de agencia evidenciado fue entre los accionistas y los administradores, pues, como consecuencia de cada una de las transacciones realizadas y el ocultamiento de las cifras reales de la compañía, los accionistas vieron perjudicado el valor de sus acciones y con ello la posibilidad de su negociación a un valor real y la probabilidad de obtener utilidades importantes al final del ejercicio social. ${ }^{64}$ Esto denota que la actuación de los administradores estuvo encaminada a buscar un crecimiento exponencial de la empresa a través de su participación en transacciones que comportaron un gran riesgo y, aunque esto generaba en el corto plazo una maximización del valor que los accionistas tenían en la compañía, en el largo plazo llevó a las consecuencias enunciadas. ${ }^{65}$

A buen criterio de William Bratton, el caso de Enron es solo uno de los grandes ejemplos donde se puede evidenciar que la práctica de las compañías encaminada a maximizar los beneficios para sus accionistas implica, necesariamente, una inversión impaciente que tiene como consecuencia una obsesión por las cifras a corto plazo y también "significa una gestión agresiva de las cifras reportadas en respuesta a las demandas de valor inmediato de la comunidad inversora". ${ }^{66}$

De esta manera, el problema de agencia entre los administradores y los accionistas seguirá latente en la medida que los administradores de las sociedades de capital disperso sigan dando prevalencia a la aplicación del modelo de primacía de los accionistas al momento de tomar decisiones a corto plazo para encaminar el rumbo inmediato de la sociedad y obtener bonificaciones por su gestión. Al adoptar estas decisiones, olvidan los impactos que estas producen en el largo plazo, contravienen el modelo de shareholder primacy y agravan el problema de agencia al perjudicar en el largo plazo los intereses de los accionistas.

\footnotetext{
Idem.

Idem.

Idem.

William Bratton, "Enron and the dark side of shareholder value", en Tulane Law Review 76 (2002), pp. 12751361 , p. 1284 ("It also means aggressive management of reported figures responsive to the investment community's demands for immediate value").
} 
Por otro lado, indiscutiblemente, con la aplicación del modelo de primacía de los accionistas, los administradores están lejos de tener el deber de considerar el bienestar de otros stakeholders, como los empleados o acreedores de la compañía. Lo anterior se refuerza con el hecho de que las cortes de Delaware han rechazado explícitamente que "la administración tenga deberes fiduciarios con otras partes interesadas a expensas de los accionistas, al menos mientras la compañía no opere en las inmediaciones de la insolvencia. Por lo tanto, las partes interesadas no pueden iniciar un litigio para que la administración considere sus intereses". ${ }^{67}$

En consecuencia, con la aplicación del shareholder primacy model en países como Estados Unidos, donde prevalecen las compañías con capital disperso, se pueden generar problemas de agencia, principalmente entre los administradores (agente) y los accionistas (principal) y entre la empresa (agente) y otros grupos de interés (principal). Así, en aplicación de este modelo los problemas de agencia pueden incrementar como en los casos Ford contra Dodge, Valeant y Enron, donde decisiones tomadas con el objetivo de percibir ganancias en el corto plazo afectaron no solo a otras partes interesadas, como empleados, consumidores y acreedores, sino que terminaron por perjudicar a los mismos accionistas que, en el largo plazo, vieron disminuidas sus ganancias y el valor que tenían representado en la compañía.

Sin embargo, la dominancia del modelo de primacía de los accionistas y las decisiones a corto plazo no ocurren solo en países donde existe dispersión de capital. A continuación, veremos que en países donde prevalecen compañías con una estructura de capital concentrado, como en Colombia, el shareholder primacy model puede conducir a la existencia de problemas de agencia y al cortoplacismo societario.

\section{Colombia: la necesidad de repensar el modelo y consagrar no solo derechos, sino deberes de los accionistas para mitigar los problemas de agencia y el cortoplacismo societario}

Una vez desarrollado el caso estadounidense donde predominan las compañías de capital disperso, se pasará a Colombia, un país donde prevalecen las compañías con capital concentrado. En primer lugar, se abordará la concentración del capital en este país a través de cifras y, en segundo lugar, la prevalencia del

67 Jill Fisch, "Measuring efficiency in corporate law: The role of shareholder primacy", en Journal of Corporation Law 31 (3) (2006), p. 653. Simons c. Cogan, 549 A.2d 300, 303 (Del. 1988) ("management has a fiduciary obligation to other stakeholders at the expense of shareholders, at least as long as the corporation is not operating in the vicinity of insolvency. Consequently, stakeholders cannot initiate litigation to require that management consider their interests"). 
shareholder primacy model en las normas colombianas y en los fallos judiciales, a pesar de la consagración de la función social de la empresa en la Constitución Política. Finalmente, se hará referencia a la necesidad de comenzar a dialogar acerca de los deberes de los accionistas en las sociedades de capital, ya que es abundante la referencia a sus derechos, pero no se han explorado a profundidad sus deberes con la compañía y con otros grupos de interés.

Como consta en el Informe de indicadores de gobierno corporativo en empresas de capital cerrado año 2018, de la Superintendencia de Sociedades, de la información reportada por 6.204 empresas que presentaron el Informe 42 de Prácticas Empresariales en el año 2018, el 49,71 \% de las compañías tienen de 5 a 10 socios, $28,64 \%$ tiene uno o dos socios, ${ }^{68}$ y más del $92 \%$ de las empresas tienen menos de 11 socios, lo que muestra que el capital en Colombia está concentrado (figura 1).

Figura 1. Número de socios o accionistas de las compañías en Colombia ${ }^{69}$

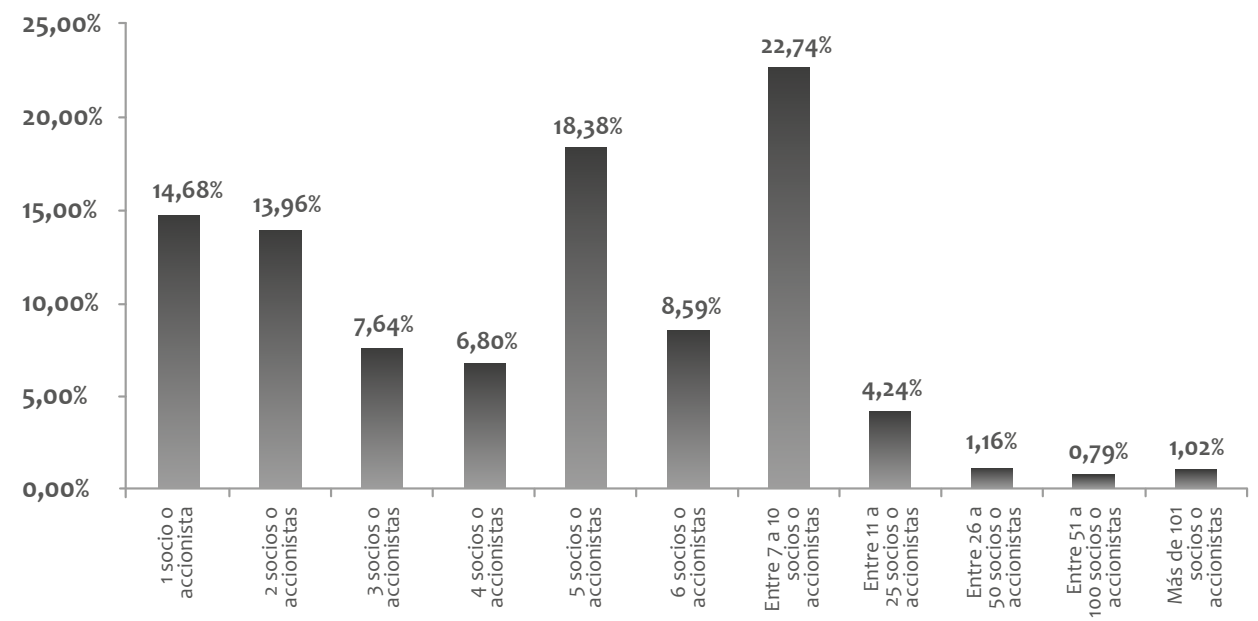

Fuente: Superintendencia de Sociedades, “Indicadores de gobierno corporativo en empresas de capital cerrado año 2018", 15 de diciembre de 2019.

De acuerdo con Dyck y Zingales, la alta concentración de la propiedad en América Latina podría deberse a los beneficios privados de control. Estos autores midieron, a partir de la magnitud de la prima de control, lo que pagan los adquirentes por obtener el control de la compañía versus el precio al cual están transando las acciones inmediatamente después del anuncio de la com-

68 Superintendencia de Sociedades, "Indicadores de gobierno corporativo en empresas de capital cerrado año 2018", 15 de diciembre de 2019, en https://www.supersociedades.gov.co/Noticias/Paginas/2019/Supersociedades-presenta-informe-sobre-el-Gobierno-Corporativo-en-las-empresas-colombianas.aspx, fecha de conIbid., p. 14. 
pra, para determinar que un controlante anticipa que va a poder extraer beneficios privados de control y por eso paga un mayor precio por las acciones. ${ }^{70}$

De esta forma, Dyck y Zingales concluyeron que en Colombia una persona que adquiere el control paga hasta 27 puntos porcentuales más del valor de mercado de la compañía y en Brasil dicha cifra llega hasta 65 puntos porcentuales más, mientras que en Estados Unidos solo paga 1 punto porcentual más por adquirir el control, probablemente porque en esta última jurisdicción el potencial de extracción es menor y no vale la pena invertir en el control porque no hay mayor diferencia en los beneficios privativos que se pueden obtener.

Figura 2. Concentración de la propiedad en

América Latina según la OCDE

\begin{tabular}{|l|c|c|c|c|}
\hline \multicolumn{7}{|c|}{ Concentración de la propiedad } \\
\hline País & $\begin{array}{c}\text { Muestra } \\
(2002)\end{array}$ & $\begin{array}{c}\text { \% del accionista } \\
\text { principal (2002) }\end{array}$ & $\begin{array}{c}\text { \% de los 3 accionistas } \\
\text { principales (2002) }\end{array}$ & $\begin{array}{c}\text { \% de los 5 accionistas } \\
\text { principales (2002) }\end{array}$ \\
\hline Argentina** & 15 & 61 & 82 & 90 \\
\hline Brasil $^{*}$ & 459 & 51 & 65 & 67 \\
\hline Chile* $^{*}$ & 260 & 55 & 74 & 80 \\
\hline Colombia* $^{*}$ & 74 & 44 & 65 & 73 \\
\hline México** $^{*}$ & 27 & 52 & 78 & 82 \\
\hline Perú* & 175 & 57 & 73 & 79 \\
\hline Promedio & 168,3 & 53 & 73 & 83 \\
\hline
\end{tabular}

* Datos de ECONOMATICA.

** Datos de presentaciones de 20-F ADR.

Fuente: OCDE, "White Paper" sobre Gobierno Corporativo en América Latina, 2004, p. 65.

Una vez establecido que Colombia es un país donde predomina el capital concentrado (figura 2), es importante ahora desarrollar que se trata de un país en el que la administración de las sociedades está guiada por el deber de lealtad y cuidado de los administradores a los asociados, en aplicación del shareholder primacy model.

El artículo 98 del Código de Comercio define a la sociedad como un contrato por el cual dos o más personas se obligan a hacer un aporte con el fin de repartirse entre sí las utilidades obtenidas en la empresa o actividad social. Por lo tanto, las utilidades son un elemento esencial del contrato de sociedad y, como tal, sin las mismas no produce efecto alguno o degenera en otro contrato diferente (art. 1501, Código Civil). ${ }^{71}$ 
Es tal la importancia que el legislador le ha dado a las utilidades en las sociedades de capital en Colombia, que estableció montos mínimos repartibles en los artículos 155 y 454 del Código de Comercio y mayorías calificadas del $78 \%$ si la suma de las reservas legal, estatutarias y ocasionales excede del $100 \%$ del capital suscrito y se quiere distribuir menos del $30 \%$ de las utilidades, prohibiciones que fueron eliminadas para las sociedades por acciones simplificadas en virtud del artículo 38 de la Ley 1258 de 2008.

Incluso, los accionistas minoritarios, sin actuar en el mejor interés de la compañía, algunas veces consideran injustificada la creación de reservas que son necesarias para la empresa y señalan que esta "retención de utilidades" se hace con el fin de forzarlos a vender su participación accionaria. En consecuencia, es importante asignarles a los accionistas minoritarios deberes, tales como el de actuar en el mejor interés de la compañía a largo plazo y no seguir su propio interés de lucro a corto plazo.

Por otro lado, la Ley 222 de 1995, en su artículo 23 consagra los deberes de los administradores ${ }^{72}$ y señala que sus actuaciones "se cumplirán en interés de la sociedad, teniendo en cuenta los intereses de sus asociados", empero, no se refiere a los demás grupos de interés.

No obstante, debe advertirse que los acreedores son un grupo de interés que, en todo caso, sí se encuentra protegido por el derecho societario $y$, de este modo, son una excepción. La protección de los acreedores a través del derecho de sociedades sirve para mitigar los problemas de agencia con sujetos que asumen riesgos directamente relacionados con la estructura del vehículo societario y para no desincentivar a los acreedores de financiar a las compañías.

Teniendo en cuenta que puede haber un oportunismo de los asociados que perjudique a los acreedores mediante la dilución o sustitución de activos, o dilución de pasivos, ${ }^{73}$ el derecho interviene, por ejemplo, a través de las acciones paulianas (art. 2491, Código Civil), las acciones revocatorias (art. 74, Ley 1116 de 2006 y art. 572, Código General del Proceso) y, el derecho de sociedades consagra la desestimación de la personalidad jurídica (art. 42, Ley 1258 de 2008 y art. 24, núm. 5(d), Código General del Proceso). ${ }^{74}$

72 Congreso de la República de Colombia, Ley 1258 de 2008. El artículo 27 de la Ley 1258 de 2008 establece que "las reglas relativas a la responsabilidad de administradores contenidas en la Ley 222 de 1995" les serán aplicables a los administradores de las sociedades por acciones simplificadas.

73 Gerard Hertig, Hideki Kanda y John Armour, "Transactions with Creditors", en AA.VV., The Anatomy of Corporate Law A Comparative and Functional Approach, 3 ed., Oxford, Oxford University Press, 2017, pp. 109-143.

74 Sobre la desestimación de la personalidad jurídica, véase Superintendencia de Sociedades, Auto 801-16441 del 3 de octubre de 2013, RCN Televisión S.A. contra Media Consulting Group S.A.S., rad. 2013-801-126. Superintendencia de Sociedades, Sentencia 800-122 del 11 de diciembre de 2017, Panavias Ingeniería \& Construcciones S.A. en reorganización contra Agro Repuestos S.A.S. en liquidación y otros, rad. 2015-01-419998. 
Ahora bien, algunos podrían sostener que el artículo 333 de la Constitución Política establece que "la empresa, como base del desarrollo, tiene una función social que implica obligaciones" y que, como lo ha señalado la Corte Constitucional, "es obligación de los empresarios estarse al fin social y a los límites del bien común que acompañan el ejercicio de la citada libertad" económica. ${ }^{75}$ Así, podría pensarse que la constitucionalización del derecho privado permea el derecho de sociedades y le impone el deber a los accionistas y a los administradores de considerar otros grupos de interés en cumplimiento de las obligaciones que la función social le asigna a la empresa. No obstante, esto está lejos de ser una realidad.

El caso que se trae a colación para demostrar la primacía de los accionistas en Colombia sobre otros grupos de interés es el de una compañía cerrada de capital concentrado con menos de diez accionistas, cuyo término de duración vencía en 2020. Aunque los accionistas mayoritarios habían votado favorablemente la ampliación del término de duración, no se había logrado obtener la mayoría calificada necesaria para aprobar la reforma estatutaria porque los accionistas minoritarios no asistían a las reuniones extraordinarias de accionistas convocadas para tal fin.

Ante la renuencia de los accionistas minoritarios de asistir a las asambleas y aprobar la prórroga de la vigencia de la sociedad, más de 70 empleados de la compañía, que con su filial generan directa e indirectamente cerca de 500 empleos, interpusieron una acción de tutela contra los accionistas minoritarios en defensa de los derechos fundamentales al trabajo, a la salud, al mínimo vital en conexidad con la vida digna, y a la seguridad social, ya que algunos de los accionantes en la tutela eran prepensionados, otros tenían condiciones de discapacidad, otros eran mujeres en estado de embarazo y madres cabeza de familia.

Los trabajadores que interpusieron la tutela alegaron que, según la Constitución Política de Colombia, la empresa tiene una función social que implica obligaciones y que la liquidación de la compañía vulneraría gravemente sus derechos fundamentales dado que perderían su empleo en plena pandemia del covid-19. A pesar de lo anterior, la juez de tutela negó el amparo y consideró que:

... es imperativo añadir que, por un lado, la acción de tutela no puede usarse para obligar a una persona jurídica o natural a actuar de determinada manera o para que adopte cierta decisión solo para beneficiar los intereses del accionante, máxime si la conducta u omisión que se reprocha no es contraria a la Ley e incluso esta la permite. En ese sentido, nótese que en el Código de Comercio está previsto el vencimiento del término de duración de la sociedad sin que se hubiera prorrogado

$75 \quad$ Corte Constitucional, Sentencia C-815 de 2001. 
oportunamente como una causal para su disolución y posterior liquidación [...] Y aunque posiblemente esa determinación repercutirá en otras personas, no por ello es motivo para acudir a esta acción constitucional. ${ }^{76}$ (Énfasis agregado)

Debido a este tipo de decisiones, es imperiosa la necesidad de pasar del modelo de primacía de los accionistas al modelo de los stakeholders, en el que las compañías y los administradores deban considerar el bienestar de otras partes interesadas y no solo el de los asociados. ${ }^{77}$ Por tal razón, los administradores deberían tener una función mediadora entre los diferentes grupos de interés.

Adicionalmente, la Ley 222 de 1995 impone deberes a los administradores y dentro de esta definición no se encuentran cobijados los accionistas. Aunque, conforme al parágrafo del artículo 27 de la Ley 1258 de 2008, los accionistas mayoritarios de las sociedades por acciones simplificadas podrían considerarse administradores de hecho si se inmiscuyen en una actividad positiva de gestión, administración o dirección de la sociedad, para mitigar el cortoplacismo societario de los asociados es conveniente que los deberes de los administradores se extiendan expresamente a todos los accionistas, mayoritarios y minoritarios. ${ }^{78}$

A manera de ejemplo, asignar el deber expreso de actuar en el mejor interés de la compañía a largo plazo a los accionistas minoritarios, y no seguir su propio interés de lucro a corto plazo, podría reducir el problema de agencia entre el minoritario (agente) con el mayoritario (principal), la empresa (principal) y otros grupos de interés (principal). Así, se mitigaría la presión del minoritario por recibir dividendos en el corto plazo, cuando el mejor interés de la compañía es el largo plazo; se reduciría su oposición a realizar capitalizacio-

76 Juzgado Noveno de Pequeñas Causas y Competencia Múltiple de Bogotá, Sentencia de tutela del 4 de agosto de 2020, rad. 2020-00083.

77 Puede pensarse, por ejemplo, en el caso de Mónica Colombia S.A.S. donde la Superintendencia de Sociedades estableció que "la estructura del Grupo Empresarial Mónica Colombia no obedeció a una finalidad legítima de negocios, sino que ese artificioso entramado societario fue, precisamente, el instrumento que permitió burlar las limitaciones contempladas para el otorgamiento de incentivos a la capitalización rural [...], [a través de] la figura de la interposición societaria con la finalidad específica de evadir los topes legales correspondientes". Así, los accionistas como agentes actuaron en su propio interés sin consideración de los principales: el Estado y otros grupos de interés como las compañías que sí querían acceder legítimamente al incentivo a la capitalización rural (Superintendencia de Sociedades, Sentencia 800-55 de 16 de octubre de 2013, Finagro S.A. en contra de Mónica Colombia S.A.S. y otros, rad. 2013-01-405476, p. 40).

78 Congreso de la República de Colombia, Ley 222 de 1995. Se podría extender a los accionistas el deber de lealtad de actuar en el mejor interés de la compañía y extender otros deberes del artículo 23 de la Ley 222 de 1995 como:

1. Realizar los esfuerzos conducentes al adecuado desarrollo del objeto social.

2. Velar por el estricto cumplimiento de las disposiciones legales o estatutarias.

3. Velar por que se permita la adecuada realización de las funciones encomendadas a la revisoría fiscal.

4. Guardar y proteger la reserva comercial e industrial de la sociedad.

5. Abstenerse de utilizar indebidamente información privilegiada.

6. Dar un trato equitativo a todos los socios y respetar el ejercicio del derecho de inspección de todos ellos.

7. Abstenerse de participar por sí o por interpuesta persona en interés personal o de terceros, en actividades que impliquen competencia con la sociedad o en actos respecto de los cuales exista conflicto de intereses, salvo autorización expresa de la junta de socios o asamblea general de accionistas.

En el deber número 6 podría pensarse en el deber de no abusar del derecho de inspección a cargo de los accionistas. 
nes que son necesarias para la compañía y podría evitar que los minoritarios abusen de su derecho a liquidar empresas financieramente viables, a costa de perjudicar a empleados, proveedores, clientes de la compañía y otras partes interesadas (stakeholders).

El artículo 379 del Código de Comercio establece los derechos de los accionistas de las sociedades anónimas, entre los que se encuentra el derecho a recibir una parte proporcional de los beneficios sociales, no obstante, no hace referencia a ningún deber de los accionistas. De forma general, en diferentes conceptos, la Superintendencia de Sociedades ha reconocido que los accionistas, además de derechos, tienen deberes como el respeto a los estatutos sociales:

... el sistema jurídico colombiano les garantiza a todos los mismos derechos y les impone las correlativas responsabilidades y obligaciones, que, como accionistas o socios, tienen en las empresas constituidas bajo la forma jurídica societaria regulada por el Código de Comercio. ${ }^{79}$

En cuanto a los deberes que indudablemente tiene todo accionista, se circunscriben a respetar en un todo los estatutos sociales que rigen la vida jurídica entre los asociados y la compañía. ${ }^{80}$ (Énfasis agregado)

Igualmente, vía jurisprudencial la Superintendencia de Sociedades sostiene que existen deberes de los accionistas derivados del principio de buena fe y de la prohibición de abusar de los derechos. De esta forma, la Superintendencia afirma que "los accionistas mayoritarios tienen el deber de asegurar que la cesión [de los activos y pasivos] se haga por un precio justo y que la compañía reciba una contraprestación adecuada" ${ }^{81}$ Lo anterior encuentra sustento en el principio de buena fe ya que "la Corte Suprema de Justicia ha explicado que el principio de buena fe a que alude el artículo 1603 del Código Civil lleva implícito el deber de que las partes contratantes se comporten lealmente". ${ }^{82}$

Del mismo modo, se fundamenta en el artículo 43 de la Ley 1258 de 2008 sobre abuso del derecho y las reglas de abuso resultan aplicables a otros tipos societarios -diferentes a las sociedades por acciones simplificadas- en virtud del artículo 252 de la Ley 1450 de 2011 y el artículo 24 numeral 5(e) del Código General del Proceso. ${ }^{83}$ Incluso, sobre el abuso del derecho de veto de los asociados minoritarios, la Superintendencia de Sociedades ha señalado que:

79 Superintendencia de Sociedades, Oficio 220-055866 del 23 de noviembre de 2007.

80 Superintendencia de Sociedades, Oficio 220-14442 del 30 de abril de 1998, rad. 261.514

81 Superintendencia de Sociedades, Sentencia 800-119 del 17 de septiembre de 2015, Martha Cecilia López contra Comercializadora G.L. S.A.S., Luis Enrique Gil Builes y Distribuidora del Kamino S.A.S., rad. 2014-801136, p. 12.

82 Ibid., p. 13

83 Superintendencia de Sociedades, Sentencia 800-54 del 15 de mayo de 2015, Jovalco S.A.S. contra Construcciones Orbi S.A., rad. 2014-801-166, p. 2. La obligación de "respetar los derechos ajenos y no abusar de los propios" también se encuentra consagrada en el artículo 95 de la Constitución Política y en el artículo 830 del Código de Comercio. 
En los Estados Unidos, por su parte, el uso oportunista del derecho de veto ha sido entendido como una violación de los deberes fiduciarios que el minoritario le debe tanto al controlante como a la sociedad. Es posible entonces que el minoritario actúe en contra de sus deberes cuando emplea el veto para extorsionar a los demás asociados, con miras a lucrarse personalmente. ${ }^{84}$ (Énfasis agregado)

La Superintendencia de Sociedades ha enfocado su jurisprudencia en la mitigación ex post de problemas de agencia entre acreedores (principal) y accionistas (agente), entre accionistas minoritarios (principal) y accionistas mayoritarios (agente) y entre accionistas (principal) y administradores (agente). Sin embargo, sería conveniente desarrollar el deber de los accionistas, tanto mayoritarios como minoritarios, de actuar en el mejor interés de la compañía y de los demás stakeholders y la función mediadora de los administradores entre todos los grupos de interés.

Después de todo, como lo ha señalado el miembro de la Comisión Europea Michel Barnier:

Por último, pero no menos importante, los accionistas deben desempeñar plenamente
su papel. Con demasiada frecuencia, los accionistas solo están interesados en los dividen-
dos más altos posibles. Eso es comprensible, pero alimenta el cortoplacismo. Llevamos años
hablando de los derechos de los accionistas. Es hora de hablar también de las obligaciones
de los accionistas. Todas estas medidas juntas marcarán la diferencia y conducirán
a un mejor gobierno corporativo en las empresas, a una mayor responsabilidad y
más rendición de cuentas. Todavía tenemos que debatir cómo implementamos estas
medidas, pero tengo claro que no podremos confiar solo en códigos voluntarios. ${ }^{85}$
(Énfasis agregado)

Finalmente, se destacan los avances de la Ley 1901 de 2018 por medio de la cual se crean y desarrollan las sociedades comerciales de beneficio e interés colectivo (BIC) en Colombia, que "son todas aquellas compañías que sean constituidas de conformidad con la legislación vigente para tales efectos, las cuales, además del beneficio e interés de sus accionistas, actuarán en procura del interés de la colectividad y del medio ambiente", lo cual permite adoptar un modelo menos centrado en los accionistas y más dirigido a los stakeholders.

En definitiva, los stakeholders son todas las partes interesadas y, como tal, "es una categoría que incluye a los accionistas (o dueños), administradores, em-

84 Superintendencia de Sociedades, Sentencia 800-50 del 8 de mayo de 2015, Alienergy S.A. contra Álvaro José Márquez y Gestión Orgánica GEO S.A.S., rad. 2013-801-157, pp. 3 y 4.

85 Therese Strand, "An economic view on shareholder duties in corporate governance", en H. Birkmose (ed.), Shareholders' Duties, vol. 12, European Company Law Series, Países Bajos, Kluwer Law International BV, 2017, p. 51 ("Last but not least, shareholders must play their role fully. Too often, shareholders are only interested in the highest possible dividends. That is understandable but it fuels short-termism. We have spoken for years about shareholders rights. It is time to also talk about shareholders' obligations. All these measures put together will make a difference and lead to better corporate governance in companies, to more responsibility and more accountability. We still need to debate how we put these measures in place-but I am clear we will not be able to rely only on voluntary codes"). 
pleados, proveedores, acreedores y vecinos de la compañía, así como a los gobiernos locales, regionales y nacionales" ${ }^{86}$ Los intereses de cada grupo de interés son importantes $\mathrm{y}$, por eso, los administradores no deben enfocarse en atender únicamente el interés de los accionistas (shareholder primacy model), sino en tener un rol mediador en el que los intereses de los stakeholders deben ser atendidos al mismo tiempo que se actúa en el mejor interés de la compañía ya que, después de todo, la sociedad de capital es el centro que une a todas las partes interesadas. ${ }^{87}$

\section{Conclusiones}

Para analizar el cortoplacismo societario como una expresión del modelo de primacía de los accionistas y plantear la necesidad de repensar dicho modelo para adoptar el stakeholder model, se han desarrollado los casos de Estados Unidos y Colombia. Con base en el análisis comparativo realizado, se puede concluir que la primacía del shareholder primacy model puede acentuar los problemas de agencia que existen entre la compañía (agente) y los stakeholders (principal) y entre los administradores (agente) y los accionistas (principal) a largo plazo.

De esta manera, independientemente de si el shareholder primacy model se aplica en un país como Colombia, donde la estructura corporativa de la mayoría de compañías se caracteriza por tener un capital concentrado, o en un país como Estados Unidos, donde el capital suele ser disperso, el modelo hace que los socios sean el elemento central frente al cual se deben movilizar todos los esfuerzos de la administración y el logro de objetivos de la empresa, sin tener en cuenta a otros grupos que tienen interés en esta y sobre los cuales repercuten las decisiones sociales en el corto y largo plazo.

Las decisiones tomadas por los administradores, bajo el shareholder primacy model, para aumentar las ganancias de los accionistas a corto plazo podría hacerse a costa de otros grupos de interés, lo que generaría externalidades negativas, y podría poner en riesgo el futuro de la compañía y las inversiones de los propios accionistas a largo plazo.

Como se indicó, este modelo resta importancia a todas las demás partes interesadas en la compañía y puede desencadenar en otros problemas de agencia. Por tal razón, es necesario repensar su dominancia y abogar por el stakeholder model, que considera también a los accionistas como grupo de interés, pero que no los hace el centro de la gestión del administrador. 
Por un lado, los administradores deben adoptar un rol mediador entre los diferentes grupos de interés y tener como el centro de su gestión el mejor interés de la compañía en el largo plazo. No debe olvidarse que la empresa es el nexo que une a todos los demás stakeholders. Los administradores no pueden perseguir el interés cortoplacista de lucro de los accionistas a expensas de los demás interesados y en perjuicio de la compañía a largo plazo.

Por otro lado, los accionistas también deben asumir responsabilidad y es momento de comenzar a dialogar desde la academia sobre la asignación de deberes expresos a estos, más allá de la buena fe y la prohibición de abusar de los derechos, ya que hasta el momento el enfoque ha sido principalmente en los derechos de los accionistas y en cómo protegerlos.

\section{Bibliografía}

Alexander, Frederick, "Fiduciary duties for conventional corporations enforcing shareholder primacy", en Benefit Corporation Law and Governance: Pursuing Profit with Purpose, Oakland, Berrett-Koehler Publishers, 2018.

Armour, John, Luca Enriques, Henry Hansmann y Reinier Kraakman, "The basic governance structure: The interests of shareholders as a class", en European Corporate Governance Institute (ECGI), Law Working Paper (337) (2017). DOI: https://doi.org/10.2139/ssrn.2901416

Aspen Institute Business \& Society Program, "Overcoming short-termism: A call for a more responsible approach to investment and business management", 16 de septiembre de 2009, en https://www.aspeninstitute.org/publications/ overcoming-short-termism-call-more-responsible-approach-investmentbusiness-management/, fecha de consulta: 12 de septiembre de 2020.

Bainbridge, Stephen, "In defense of the shareholder wealth maximization norm: A reply to professor Green", en Washington \& Lee Law Review 50 (4) (1993), pp. 1423-1447.

Beale, Frederick y Mario Fernando, "Short-termism and genuineness in environmental initiatives: A comparative case study of two oil companies", en European Management Journal 27 (1) (2009), pp. 26-35. DOI: https://doi. org/10.1016/j.emj.2008.05.002

Bebchuk, Lucian, "The case for increasing shareholder power", en Harvard Law Review 118 (3) (2005), pp. 833-914.

Berle, Adolf y Gardiner Means, The Modern Corporation \& Private Property, 2 ed., New York, Routledge Taylor \& Francis Group, 1932.

Blair, Margaret y Lynn Stout, "A team production theory of corporate law", en Virginia Law Review 85 (2) (1999), pp. 247-328. DOI: https://doi. org/10.2307/1073662 
Bower, Joseph y Lynn Paine, "The error at the heart of corporate leadership", en Harvard Business Review, en https://hbr.org/2017/05/managing-for-thelong-term, fecha de consulta: 20 de septiembre de 2020.

Bratton, William, "Enron and the dark side of shareholder value", en Tulane Law Review 76 (2002), pp. 1275-1361. DOI: https://doi.org/10.2139/ssrn.301475

Bushee, Brian, "The influence of Institutional Investors on Myopic R\&D Investments Behavior", en The Accounting Review 73 (1998), pp. 305-306.

Business Roundtable, "Business Roundtable redefines the purpose of a corporation to promote 'an economy that serves all americans'"', 19 de agosto de 2019, en https://www.businessroundtable.org/business-roundtable-redefines-the-purpose-of-a-corporation-to-promote-an-economy-that-servesall-americans, fecha de consulta: 12 de septiembre de 2020.

Citron Research, "Valeant: Could this be the Pharmaceutical Enron?", 21 de octubre de 2015, en https://citronresearch.com/wp-content/uploads/2015/10/ Valeant-Philador-and-RandO-final-a.pdf, fecha de consulta: 20 de septiembre de 2020.

Citron Research, "Why a congressional subpoena to Valeant about price gouging on drugs should be granted", 28 de septiembre de 2015, en https:// citronresearch.com/wp-content/uploads/2015/09/valeant-part-1-final.pdf, fecha de consulta: 20 de septiembre de 2020.

Coffee, John, "The future as history: The prospects for global convergence in corporate governance and its implications", en Northwestern University Law Review 93 (3) (1999), p. 641.

Dent, George, "The essential unity of shareholders and the myth of investor short-termism", en Delaware Journal of Corporate Law 35 (1) (2010), pp. 126-128.

Diario La Vanguardia, “Enron: el mayor escándalo financiero de la historia, tan grande como olvidado", 2 de diciembre de 2016, en https://www.lavanguardia.com/economia/20161202/412319658496/enron-quiebra-escandalo. html, fecha de consulta: 5 de junio de 2021.

Dodge c. Ford Motor Co., 204 Mich. 459, 170 N.W., 668, 1919.

Duruigbo, Emeka, “Tackling shareholder short-termism and managerial myopia", en Kentucky Law Journal 100 (3) (2011-2012), pp. 531-584. DOI: https:// doi.org/10.2139/ssrn.1802840

Dyck, Alexander y Luigi Zingales, "Private benefits of control: An international comparison", en The Journal of Finance 59 (2) (2004), pp. 537-600. DOI: https://doi.org/10.1111/j.1540-6261.2004.00642.x 
Fisch, Jill, "Measuring efficiency in corporate law: The role of shareholder primacy", en Journal of Corporation Law 31 (3) (2006). DOI: https://doi. org/10.2139/ssrn.878391

Friedman, Milton, "A Friedman doctrine-The Social Responsibility of business is to increase its profits", 13 de septiembre de 1970, en https://www. nytimes.com/1970/09/13/archives/a-friedman-doctrine-the-social-responsibility-of-business-is-to.html, fecha de consulta: 5 de junio de 2021

George, Bill, "Another view: Can biotech survive icahn", 3 de junio de 2010, en https://dealbook.nytimes.com/2010/06/03/another-view-can-biotechsurvive-icahn/, fecha de consulta: 13 de septiembre de 2020.

Gibney, Alex y Brian McGinn, "Dirty Money: Short selling and pharmaceuticals", 2018, en www.netflix.com, fecha de consulta: 12 de septiembre de 2020.

Gibney, Alex, "Enron: The smartest guys in the room", en Amazon Prime Video, 2005, en www.primevideo.com, fecha de consulta: 5 de junio de 2021.

Hansmann, Henry y Reinier Kraakman, "The end of history for corporate law", en Georgetown Law Journal 89 (2) (2001), pp. 439-468.

Hazen, Thomas, "The short-term/long-term dichotomy and investment theory: Implications for securities market regulation and for corporate law", en North Carolina Law Review 70 (1) (1991), pp. 137-207.

Henderson, Todd, "Everything old is new again: Lessons from Dodge v. Ford Motor Company", en John M. Olin Program in Law and Economics, Working Paper (373) (2007). DOI: https://doi.org/10.2139/ssrn.1070284

Hertig, Gerard, Hideki Kanda y John Armour, "Transactions with Creditors", en AA.VV., The Anatomy of Corporate Law. A Comparative and Functional Approach, 3 ed., Oxford, Oxford University Press, 2017, pp. 109-143. DOI: https://doi.org/10.1093/acprof:oso/9780198739630.003.0005

Kraakman, Henry, Reinier Hansman y John Armour, "Agency problems and legal strategies", en AA. VV., The Anatomy of Corporate Law A Comparative and Functional Approach, 3 ed., Oxford, Oxford University Press, 2017.

La Porta, Rafael, Florencio López de Silanes y Andrei Shleifer, "Corporate ownership around the world", en The Journal of Finance 54 (2) (1999). DOI: https://doi.org/10.1111/0022-1082.00115

Lahart, Justin, "Wrong way? Street signs point to speed", en The Wall Street Journal, 26 de febrero de 2007, en https://www.wsj.com/articles/ SB117244638061618757, fecha de consulta: 13 de septiembre de 2020.

Lee, Louise, "It's time to value stakeholders over shareholders", en Stanford Business, 4 de mayo de 2018, en https://www.gsb.stanford.edu/insights/ 
its-time-value-stakeholders-over-shareholders, fecha de consulta: 20 de septiembre de 2020.

Martínez-Echevarría, Alfonso, "The nature of shareholding and regulating shareholders' duties", en H. Birkmose (ed.), Shareholders' Duties, European Company Law Series vol. 12, Países Bajos, Kluwer Law International BV, 2017.

Mitchell, Lawrence, "A critical look at corporate governance", en Vanderbilt Law Review 45 (5) (1992), pp. 1263-1318.

OCDE, “White Paper" sobre Gobierno Corporativo en América Latina, OCDE, 2004.

O'Connor, Marleen, “Organized labor as shareholder activist: Building coalitions to promote worker capitalism", en University of Richmond Law Review 31 (5) (1997), pp. 1345-1398.

Posner, Richard, El análisis económico del derecho, 7 ed., México: Fondo de Cultura Económica, 2007.

Reyes Villamizar, Francisco, Análisis económico del derecho de sociedades, 2 ed., Bogotá, Legis, 2013.

Reyes Villamizar, Francisco, Derecho Societario, 2 ed., Bogotá, Temis, 2011.

Schacht, Kurt, "Breaking the short-term cycle", en Fourth Annual Director's Institute on Corporate Governance (2006), pp. 583-591.

Stout, Lynn, "The toxic side effects of shareholder primacy", en University of Pennsylvania Law Review 161 (7) (2013), pp. 2003-2023.

Strand, Therese, "An economic view on shareholder duties in corporate governance", en H. Birkmose (ed.), Shareholders' Duties, European Company Law Series vol. 12, Países Bajos, Kluwer Law International BV, 2017.

Strine, Leo, "The dangers of denial: The need for a clear-eyed understanding of the power and accountability structure established by the Delaware general corporation law", en Wake Forest Law Review 50 (2015).

Superintendencia de Sociedades, "Indicadores de gobierno corporativo en empresas de capital cerrado año 2018", 15 de diciembre de 2019, en https:// www.supersociedades.gov.co/Noticias/Paginas/2019/Supersociedadespresenta-informe-sobre-el-Gobierno-Corporativo-en-las-empresas-colombianas.aspx, fecha de consulta: 5 de junio de 2021.

The Guardian, "The Volkswagen emissions scandal explained", 23 de septiembre de 2015, en https://www.theguardian.com/business/ng-interactive/2015/sep/23/volkswagen-emissions-scandal-explained-diesel-cars, fecha de consulta: de 5 de junio de 2021. 
U.S. Security and Exchange Comission, "SEC Registration: Bausch Health Companies Inc.", 04 de noviembre de 2019, en https://sec.report/CIK/0000885590, fecha de consulta: 5 de junio de 2021.

Welsh, Michelle, Peta Spender, Irene Lynch Fannon y Kath Hall, "The end of the 'End of History for Corporate Law'?", en Australian Journal of Corporate Law 29 (2014), pp. 147-168.

World Economic Forum, “QQué tipo de capitalismo queremos?”, 2 de diciembre de 2019, en https://es.weforum.org/agenda/2019/12/que-tipo-de-capitalismo-queremos/, fecha de consulta: 5 de junio de 2021.

World Economic Forum, "Manifiesto de Davos 2020: el propósito universal de las empresas en la Cuarta Revolución Industrial", 2 de diciembre de 2019, en https://es.weforum.org/agenda/2019/12/manifiesto-de-davos-2020-elproposito-universal-de-las-empresas-en-la-cuarta-revolucion-industrial/ fecha de consulta: 5 de junio de 2021.

\section{Normas y jurisprudencia}

Congreso de la República de Colombia, Ley 1258 de 2008.

Congreso de la República de Colombia, Ley 222 de 1995.

Corte Constitucional, Sentencia C-815 de 2001.

Dodge c. Ford Motor Co., 204 Mich. 459, 170 N.W., 668, 1919.

eBay Domestic Holdings, Inc. c. Newmark, 16 A.3d 1 (Del. Ch. 2010).

Hunter c. Robert, Throp \& Co., 83 Mich 63, 71, 47 N. W. 131.

Juzgado Noveno de Pequeñas Causas y Competencia Múltiple de Bogotá, Sentencia de tutela del 04 de agosto de 2020, rad. 2020-00083.

Simons c. Cogan, 549 A.2d 300, 303 (Del. 1988).

Superintendencia de Sociedades, Auto 801-16441 del 3 de octubre de 2013, RCN Televisión S.A. contra Media Consulting Group S.A.S., rad. 2013-801-126.

Superintendencia de Sociedades, Oficio 220-055866 del 23 de noviembre de 2007.

Superintendencia de Sociedades, Oficio 220-14442 del 30 de abril de 1998, rad. 261.514.

Superintendencia de Sociedades, Sentencia 800-119 del 17 de septiembre de 2015, Martha Cecilia López contra Comercializadora G.L. S.A.S., Luis

Enrique Gil Builes y Distribuidora del Kamino S.A.S., rad. 2014-801-136. 
Superintendencia de Sociedades, Sentencia 800-122 del 11 de diciembre de 2017, Panavías Ingeniería \& Construcciones S.A. en reorganización contra Agro Repuestos S.A.S. en liquidación y otros, rad. 2015-01-419998.

Superintendencia de Sociedades, Sentencia 800-50 del 8 de mayo de 2015, Alienergy S.A. contra Álvaro José Márquez y Gestión Orgánica GEO S.A.S., rad. 2013-801-157.

Superintendencia de Sociedades, Sentencia 800-54 del 15 de mayo de 2015, Jovalco S.A.S. contra Construcciones Orbi S.A., rad. 2014-801-166. 